\title{
Do government-initiated energy comparison sites encourage consumer search and lower prices? Evidence from an online randomized controlled experiment in Australia
}

\author{
Md. Main Uddin \\ Department of Economics \\ Monash Business School \\ Monash University \\ Melbourne, Victoria, Australia \\ Email: md.uddin@monash.edu
}

\author{
Liang Choon Wang \\ Department of Economics \\ Monash Business School \\ Monash University \\ Melbourne, Victoria, Australia \\ Email: liang.c.wang@monash.edu
}

\author{
Russell Smyth \\ Department of Economics \\ Monash Business School \\ Monash University \\ Melbourne, Victoria, Australia \\ Email: russell.smyth@monash.edu
}

\begin{abstract}
:
We conduct an Online randomized controlled experiment in Australia in order to examine whether government initiatives to encourage the use of energy comparison sites increase consumer search and result in lower prices. Despite significant price variations across energy retailers, our experiment indicates that while providing information about the potential gains from using the governmentowned Victoria Energy Compare

(VEC) website encourages participants to visit the website, it is not effective in inducing them to contact, or switch, retailers who are providing better offers. Moreover, the availability of a $\$ 50$ bonus associated with using the VEC website reduces the likelihood that lowincome participants contact, or switch retailers, in order to lower their electricity prices, leading to an increase in their electricity expenditure. Our findings imply that government-initiated comparison sites are not sufficient to promote competition and that providing consumers with financial incentives for using these sites in order to encourage competition may potentially backfire.
\end{abstract}

Keywords: VEC, Financial incentive, Energy price, Field experiment, Australia

JEL codes: H24, H31, Q43, Q48,

Acknowledgments: An earlier version of this paper was presented at a seminar at Monash University. We thank participants in the seminar, as well as Ron Ben David, Lata Gangadharan, Gordon Leslie and Bruce Mountain for very constructive comments and suggestions. The usual disclaimer applies. This project received Monash ethics approval project number 19965 .

() 2020 Md. Main Uddin, Liang Choon Wang and Russell Smyth

All rights reserved. No part of this paper may be reproduced in any form, or stored in a retrieval system, without the prior written permission of the author. monash.edu/ businesseconomics

ABN 12377614012 CRICOS Provider No. 00008C 


\section{Introduction:}

The advent of comparison sites and competitive channels has enabled consumers to use the internet with ease to compare features and prices, as well as review products and services sold by multiple sellers. Yet, despite these platforms becoming increasingly ubiquitous, price dispersions for seemingly homogenous products and services persist. There is also a concern that instead of promoting competition and lowering prices, these commercial platforms actually lead to higher prices by weakening competition between sites, reflecting the market power that they exercise and the fees that they charge (Mountain, 2019; Ronayne and Taylor, 2018; EU Competition Authorities, 2016; Hviid, 2015; BBC, 2014). Running parallel with these commercial websites, government-run, governmentaccredited or government-approved comparison websites in the energy market in Australia, New Zealand and the United Kingdom have emerged, seeking to promote competition and lower prices. ${ }^{1}$

This paper uses a randomised controlled experiment to investigate whether a government initiative to promote the use of a government-provided comparison website in an energy market is effective in lowering prices that the site users paid for their electricity. Specifically, our experiment embedded additional information in an online household energy survey to inform participants about the benefits of using the Victorian Energy Compare (VEC) website, an energy comparison website, which was initiated by the State Government of Victoria in Australia. ${ }^{2}$ The experiment allows us to answer two main questions: (1) whether the presence and promotion of comparison websites can encourage competition and lower prices in the retail energy market; and (2) whether government-provided financial incentives designed to encourage the use of comparison websites have any added effects.

The experiment assigned online survey participants into either a control group or one of two information treatment groups and collected information about their electricity consumption and expenditure in two rounds of surveys. In the baseline survey, the participants in the first treatment group received information that using the VEC website to compare energy offers available on the market could potentially save them, on average, $\$ 330$ on their annual energy bills. In addition to being given this information, participants in the second treatment group were informed in the baseline survey about the availability of a one-time $\$ 50$ Power Saving Bonus provided by the Victorian Government, which could be claimed by using the VEC website.

\footnotetext{
${ }^{1}$ In the United Kingdom, there are comparison websites accredited by the Office of Gas and Electricity Markets (Oftem). In New Zealand, the independent government entities, Electricity Authority and Consumer NZ, collaborate with a number of energy retailers to run the "Powerswitch" comparison site.

${ }^{2}$ https://compare.energy.vic.gov.au/
} 
Our experiment reveals that providing information about the potential gains from using the VEC website increased the likelihood that the average survey participant visited the website, but it failed to induce them to further contact, or switch, electricity retailers in order to lower their electricity prices. The additional information about the $\$ 50$ bonus also increased the likelihood that the average survey participant visited the website. Yet, surprisingly, the $\$ 50$ bonus actually induced low-income participants to reduce their effort in contacting, or switching, electricity retailer to lower their electricity prices, leading to an increase in their electricity expenditure. Meanwhile, high-income participants claimed the $\$ 50$ bonus, but did nothing to reduce their electricity prices, keeping their electricity consumption and expenditure unchanged. Our results indicate that promoting the benefits of government-provided price comparison websites is not an effective avenue in order to encourage competition and lower prices in the retail energy market, while using financial incentives to entice consumers to use comparison sites may actually backfire.

This paper is related to the growing literature regarding the effectiveness of demand-side information interventions in influencing energy behaviours. There is a large literature in this area, which include the effects of information labels on energy efficiency behaviours and choices, such as Newell and Siikamäki (2014) and Kallbekken et al. (2013); the effects of social norms or peer comparisons on energy consumption and conservation behaviours, such as Allcott (2011), Allcott and Rogers (2014), Brent et al. (2015) and Ferraro et al. (2011); and the effects of conservation information on energy consumption, such as Burkhadt et al. (2019) and Islam et al. (2020). Few studies, however, examine the effects of providing information and financial incentives about comparison sites on actual energy prices paid, consumption and expenditure. The study that is most closely related to ours is Tyers et al. (2019). They sent electricity consumers of two major retailers in the United Kingdom personalised letters highlighting the amount that they could save by switching to one of three cheaper tariffs on the market available to them and found that the information induced consumers to switch to cheaper retailers. The focus of our experiment, however, is broader than that in Tyers et al. (2019). By focusing on an existing comparison site that covers all electricity retailers and examining the effects of providing information about potential savings and financial incentives from using the comparison site on a range of outcomes that include actual electricity prices, consumption and expenditure, our findings shed light on the effectiveness of comparison sites and financial incentives on improving competition.

By focusing on a government-initiated comparison site, this paper contributes to the growing literature on the role of comparison sites and competitive channels in at least two ways. First, the literature on 
comparison sites and competitive channels, such as Baye and Morgan (2001), Bodur et al. (2016). Moraga-González and Wildenbeest (2008), Ronayne and Taylor (2018), and Ronayn (2019), has mainly been interested in the role of commercial comparison sites, where the site operator charges fees to firms who advertise and to consumers who use it. Our study is the first to examine the efficacy of a government-initiated energy comparison site, which does not charge access fee for consumers or firms and, indeed, in the period that we study actually paid consumers to use it.

Second, the retail electricity market is an important market to study in its own right. Electricity is a highly homogenous good, for which demand is highly inelastic in the short run (Burke and Abayasekara, 2018). Despite the presence of energy comparison sites, the retail electricity market tends to exhibit considerable retail price variation and is often dominated by a few retailers who have the major market share. Therefore, understanding whether government initiatives to promote competition via an energy comparison site has important welfare implications.

This paper also contributes to the growing literature about the design of an effective behavioural public policy. Past studies have examined the effectiveness of providing information on promoting healthy eating (Mathios, 2000; Swartz et al., 2011), integration of social norms (Johannessen and Glider, 2003; John et al., 2014), legal compliance (Blumenthal et al., 2001; Fellner et al., 2013; Hasseldine et al., 2007), energy conservation (Allcott, 2011; Costa \& Kahn, 2013) and prosocial behaviours (Frey and Meier, 2004), among others. A key objective of energy market policy has been to increase benefits flowing to consumers who are particularly vulnerable, such as high energy consumers or those on low incomes (Thwaites et al., 2017). A catalyst for this objective is a growing concern about the prevalence of energy poverty, defined broadly in terms of low-income earners facing high energy costs, in many countries (Liddell \& Morris, 2010). In the United Kingdom, where most focus on energy poverty is centred, it is estimated that between 12 per cent and 34 per cent of households live in energy poverty depending on the region (Liddell \& Morris, 2010). In Australia, Nance (2013) estimates that up to 14\% of households live in energy poverty, depending on how energy poverty is defined, and this number is likely to have increased over the last few years with recent increases in energy prices.

We focus on the extent to which policies to benefit low income consumers have been effective. Byrne et al (2019) use a field experiment to study price discrimination in the Victorian electricity market. They cite research from consumer advocacy groups in Australia and the United Kingdom that lowincome customers are least likely to search for better electricity contracts (ECA, 2017; Ofgem, 2019). Low-income consumers in Victoria receive a 17.5\% discount on their electricity bill. One of 
the issues that Byrne et al (2019) examine is whether this subsidy discourages search behaviour among this group. They note that the Victorian government is paying consumers to use the VEC website through the $\$ 50$ bonus and conjecture this might get low income vulnerable households to look around more. We extend their work to specifically address this issue, finding that it does not.

Our findings indicate that using financial incentives to promote consumer search behaviour among vulnerable consumers, can actually backfire, leading them to spend more on electricity. This finding contributes to evidence that policies designed to positively change behaviour to realize desirable outcomes can backfire in other contexts, such as the labour market (Leibbrandt \& List, 2018; Marinescu 2017), climate change policy (Druckman et al. 2011), and volunteerism (Islam et al. 2020). Our results are also consistent with studies that have found a rebound effect in energy consumption, in which policies designed to increase the use of energy efficient appliances have actually increased energy consumption (see eg. Henly et al. 1988; Lovins 1988; Brookes 1990; Grubb 1990; Brookes 2000; Greening et al. 2000; Hertwich 2005; Lin and Liu 2013).

\section{Experimental design and hypothesis}

\subsection{Background}

The VEC website is an independent Victorian Government energy comparison website (VEC 2019). It allows consumers to compare electricity, gas and solar offers in Victoria with ease and free of charge. It is arguably the most comprehensive energy comparison site available in Victoria as it contains every generally available electricity, gas and solar offer currently on the market and the information is updated every day. Retailers are required to update the VEC website about changes in offers within two days of making them publicly available. The VEC website works by taking information about household or business energy consumption and comparing what someone is paying to all the currently available energy offers on the market. After answering some questions, a VEC site user will see a range of competitive offers listed side by side on the comparison page. The offers listed are specifically tailored to the site user's own energy needs. It is then up to the site user to contact a preferred retailer to organise to switch or to use the information gathered from the site to negotiate with the current retailer for a better deal. According to the promotion information issued by the VEC website, households could save, on average, $\$ 330$ on their annual energy bills by changing their retailers and that around $70 \%$ of people using the VEC website ended up saving money. 
Following an election promise, the Victorian Government offered a $\$ 50$ Power Saving Bonus to encourage energy price comparison via the VEC website. The $\$ 50$ bonus was available to Victorian energy account holders who visited the VEC website between 1st July 2018 and 30th June 2020. However, site users were not obligated to take up an offer or switch to a retailer to receive the $\$ 50$ bonus. Once someone visited the VEC site and entered some basic information, such as their current retailer and postcode, the link for claiming the $\$ 50$ bonus would become available. ${ }^{3}$ By following the link to collect the bonus and upload a recent energy bill, the energy account holder would receive a $\$ 50$ cheque in the mail even if the person did not complete the price comparison process at the VEC website. Thus, in principle, a VEC site user could claim the bonus without viewing all the offers.

\subsection{Experiment design}

Our online experiment was designed to exploit the Victorian government's initiative to provide energy account holders the $\$ 50$ Power Saving Bonus for visiting the VEC website. Our experiment consisted of two rounds of surveys. In the baseline, survey participants were randomly assigned into either a control (C) group, or one of the two information treatment groups ( $T 1$ and $T 2$ ). The baseline survey asked all participants questions about their demographic and socio-economic characteristics, as well as questions regarding their electricity retailer, electricity consumption, electricity expenditure, and contact and search behaviours with respect to energy products. The difference between contents of the survey that participants in the control $(C)$ group and the first treatment $(T 1)$ group received is that we included the following two questions and statement to participants in $T 1$ :

(i) Have you or your household members visited the independent Victorian Government energy price comparison website "Victorian Energy Compare" (https://compare.energy.vic.gov.au/) to get information about potentially cheaper energy prices offered by various energy retailers in your residential area?

(ii) Do you know that the process of comparing the energy prices you currently pay with other offers/deals in the market using the Victoria Energy Compare website is simple and fast, and it may help you save an average of $\$ 330$ on your annual energy bill?

(iii) If you would like to visit the Victoria Energy Compare website now to find cheaper energy retailers to help save on your energy bill, please choose "Yes, take me to the site: https://compare.energy.vic.gov.au."

\footnotetext{
${ }^{3}$ The VEC website changed this feature subsequent to us completing our experiment. After the change, the link to claim the bonus only became available after completing the price comparison process.
} 
The difference between the contents of the survey that participants in the first treatment ( $T 1$ ) group and the second treatment (T2) group completed is that instead of providing the latter group with the information in (iii) above we included the following question and statement to participants in $T 2$ :

(iv) Have you or your household members claimed the Victorian Government's $\$ 50$ Power Saving Bonus by visiting the Victoria Energy Compare website and submitting the claim there?

(v) If you would like to visit the Victoria Energy Compare website now to find cheaper energy retailers to help save on your energy bill (and to claim the $\$ 50$ Power Saving Bonus from the Victorian Government), please choose "Yes, take me to the site: https://compare.energy.vic.gov.au."

The survey and information treatments were designed to answer two main research questions: (a) whether providing information about the benefits of using the government-provided comparison site and the $\$ 50$ bonus incentivizes households to compare energy deals offered by various retailers; and b) whether comparing energy offers leads households to contact, or switch, energy providers in order to get a better deal, thus lowering the electricity price that they pay and expenditure on electricity.

The online survey and randomized controlled experiment were administered by the market research company, Pure Profile, which has access to a panel who pre-registered with them to participate in online surveys on a regular basis. The survey respondents invited to participate in our online survey and experiment are stratified to be demographically representative of adult residents in the state of Victoria. They came from geographically diverse locales so the possibility of information spill over is low. All participants took part voluntarily and were compensated for their time for completing the surveys. They were also provided with an extra payment of $\$ 1.00$ to upload their electricity bills. ${ }^{4}$

At baseline, we recruited 752 participants; all of whom were invited to participate in the follow-up survey. According to our power calculations, we need a sample of approximately 300 respondents to examine our research questions. ${ }^{5}$ Our baseline sample size was targeted to be 750 because we anticipated an attrition rate of approximately 60 per cent between the two survey rounds based on Pure

\footnotetext{
${ }^{4}$ Approximately $90 \%$ of participants uploaded their electricity bills in the baseline and approximately $40 \%$ of participants uploaded their electricity bills in the follow up. This enabled us to cross check their inputs against the survey questions related to recent electricity bill and address any potential errors.

${ }^{5}$ In our power calculation, we made some assumptions about the likely effect size as a result of the treatment and also the share of households that would have claimed the bonus without the treatment. Using a simple projection based on the number of bonus claims made in early 2019 , we estimated that, in the absence of the treatment, $40 \%$ of the control group would end up claiming the bonus when we followed up with them. We assumed that the treatment would increase this share up to $60 \%$. The calculation gave us roughly 100 observations per group (at $\alpha=0.05$ and $\beta=0.80$ ).
} 
Profile's past experience. The baseline survey was conducted between June and early August of 2019 and the follow-up survey was conducted between mid-October and November of 2019. The median (mean) electricity billing cycle in our baseline sample is roughly 30 (55) days, while for $90 \%$ of participants their billing cycles were less than 90 days. We conducted the follow-up survey more than three months after the baseline survey to allow sufficient time for consumers to contact their electricity retailers to arrange better deals and for them to have new electricity bills available to report. Table 1 summarizes the sample size by control and treatment groups in each round of survey. ${ }^{6}$

Table 1: Summary of sample size

\begin{tabular}{lccc}
\hline & $\begin{array}{c}\text { Group } C \\
\text { No information }\end{array}$ & $\begin{array}{c}\text { Group } T 1 \\
\text { VEC information }\end{array}$ & $\begin{array}{c}\text { Group } T 2 \\
\text { VEC \& bonus information }\end{array}$ \\
\hline Baseline survey & 251 & 250 & 251 \\
Follow-up survey & 97 & 96 & 107 \\
Attrition rates between rounds & 0.61 & 0.62 & 0.57 \\
\hline
\end{tabular}

Notes: The attrition rates do not differ significantly across groups (p-value $>0.559)$.

\subsection{The model}

We present a simple two-period model to describe the consumer's optimisation problem and demonstrate how the two information treatments ( $T 1$ and $T 2)$ may influence the consumer's optimal effort incurred on search and contact activities in pursuit of a better deal, electricity prices paid, electricity consumption level and total electricity expenditure, relative to the control group $(C)$.

In period 1 , the consumer derives utility, $u_{1}\left(e_{1}, l_{1}\right)$ from electricity consumed, $e_{1}$, and leisure, $l_{1}$. The consumer also derives utility, $u_{2}\left(e_{2}, l_{2}\right)$, from both electricity consumption and leisure in period 2. For simplicity, the discount factor is assumed to be 1, giving the following life-time utility:

$$
u_{1}\left(e_{1}, l_{1}\right)+u_{2}\left(e_{2}, l_{2}\right)
$$

In period 1 , the consumer's total time $\left(t_{1}\right)$ is spent on work $\left(L_{1}\right)$, leisure $\left(l_{1}\right)$ and search and contact activities $\left(s_{1}\right)$, which lower the electricity price paid in period 2 :

$$
t_{1}=L_{1}+l_{1}+s_{1}
$$

\footnotetext{
${ }^{6}$ Randomization was done by sequentially assigning participants to the control and treatment groups. Specifically, the first participant to answer the survey is assigned to $C$, the second participant to $T 1$ the third participant to $T 2$, the fourth participant to $C$, fifth participant to $T 1$ and the sixth participant to $T 2$.
} 
We assume that the electricity price in period $1, p_{1}$, is given, while the electricity price in period $2, p_{2}$, is determined by search and contact activities in period 1 . The greater is $s_{1}$ the lower is the electricity price paid in period $2, p_{2} . s_{1}$ is increasing in the quantity and quality of information about alternative energy offers in the market, $I$. Thus, the price of electricity in period $2, p_{2}$, can be expressed as a function of search and contact effort spent in period $1, s_{1}$, as well as the quantity and quality of information, $I$, as follows:

$$
p_{2}=F\left(s_{1}(I)\right)
$$

Note that $F_{S}<0$ and $F_{S I}<0$. The feature that the price is decreasing in search and contact effort is similar to Gulati et al.'s (2017) model in which the price discount consumers obtain increases with their haggling effort.

Because search and contact effort activities are irrelevant in period 2, the consumer's time constraint in period 2 reduces to:

$$
t_{2}=L_{2}+l_{2}
$$

Given that the wage rate is $w_{1}$ in period 1 and $w_{2}$ in period 2 and that the consumer may also obtain a bonus, $B$, from the government, the consumer balances the following life-time budget constraint:

$$
w_{1}\left(t_{1}-l_{1}-s_{1}\right)+w_{2}\left(t_{2}-l_{2}\right)+B=p_{1} e_{1}+p_{2} e_{2}
$$

The consumer's optimisation problem yields a set of optimal consumption bundles: $e_{1}^{*}\left(p_{1}, w_{1}, B, I\right)$, $e_{2}^{*}\left(p_{1}, w_{1}, B, I\right), l_{1}^{*}\left(p_{1}, w_{1}, B, I\right), l_{2}^{*}\left(p_{1}, w_{1}, B, I\right), s_{1}^{*}\left(p_{1}, w_{1}, B, I\right), L_{1}^{*}\left(p_{1}, w_{1}, B, I\right)$, and $L_{2}^{*}\left(p_{1}, w_{1}, B, I\right)$. We are interested in the following optimal consumption bundles on which the experimental treatments are expected to have effects:

$$
s_{1}^{*}\left(p_{1}, w_{1}, B, I\right) \text { and } e_{2}^{*}\left(p_{1}, w_{1}, B, I\right)
$$

\subsubsection{The effects of information on $s_{1}^{*}, p_{2}, e_{2}^{*}$, and $p_{2} e_{2}^{*}$}

Participants in $T 1$ receive information, $I$, which can potentially decrease the price paid in period 2 via its effect on a consumer's effort to search and contact retailers for better deals:

$$
\frac{\partial p_{2}}{\partial s_{1}^{*}} \frac{\partial s_{1}^{*}\left(p_{1}, w_{1}, B, I\right)}{\partial I}<0
$$

If the information is effective in increasing the consumer's effort to search and contact retailers for better deals, then we expect the electricity price to fall in period 2. As the price paid in period 2 falls the consumer will increase electricity consumption in period 2 : 


$$
\frac{\partial e_{2}^{*}\left(p_{1}, w_{1}, B, I\right)}{\partial p_{2}} \frac{\partial p_{2}}{\partial s_{1}^{*}} \frac{\partial s_{1}^{*}\left(p_{1}, w_{1}, B, I\right)}{\partial I}>0
$$

However, the net effect on electricity expenditure in period $2, p_{2} e_{2}$, will be ambiguous because it depends on the magnitude of the price decrease, relative to the size of the increase in consumption. For example, if electricity demand is relatively price inelastic, then total expenditure will decrease.

\subsubsection{The effects of information and the bonus on $s_{1}^{*}, p_{2}, e_{2}^{*}$, and $p_{2} e_{2}^{*}$}

Participants in $T 2$ receive the same information, $I$, as participants in $T 1$, as well as being informed about the availability of the bonus, $B$. Similar to $T 1$, if the information $I$ alone is effective, we expect an effect on the effort to search and contact retailers for better deals, which, in turn, leads to a lower price in period 2, greater consumption in period 2 and an ambiguous effect on total expenditure.

The effect of the bonus, $B$, on the optimal effort to search and contact retailers is ambiguous, because it depends on the relative size of the income effect and substitution effect from receiving the bonus payment. For example, the effort to search and contact retailers for better deals may actually decrease as the consumer decides to either engage in more leisure hours with the increase in income from the bonus payment. The income effect here may work similarly to the income effect of a price rebate provided by the government in Gulati et al.'s (2017) model. According to Gulati et al. (2017), if consumers with severe liquidity constraints engage in behavioural heuristics, then a seemingly small bonus can still have a large income effect as the windfall from the bonus frees consumers from having to engage in arduous search and haggling activities. ${ }^{7}$ Thus, it is possible that the price paid in period 2 increases with the bonus payment, even when the amount may seem small:

$$
\frac{\partial p_{2}}{\partial s_{1}^{*}} \frac{\partial s_{1}^{*}\left(p_{1}, w_{1}, B, I\right)}{\partial B}>0,
$$

which implies that the bonus payment indirectly decreases electricity consumption:

$$
\frac{\partial e_{2}^{*}\left(p_{1}, w_{1}, B, I\right)}{\partial p_{2}} \frac{\partial p_{2}}{\partial s_{1}^{*}} \frac{\partial s_{1}^{*}\left(p_{1}, w_{1}, B, I\right)}{\partial B}<0
$$

On the other hand, the increase in income from the bonus can have a direct positive income effect on electricity consumption in period 2 :

\footnotetext{
${ }^{7} \mathrm{We}$ assume the time discount factor to be one in the model. If consumers discount the future heavily, then the potential price effect in period two will be heavily discounted making the income effect of the bonus in period one relatively stronger.
} 


$$
\frac{\partial e_{2}^{*}\left(p_{1}, w_{1}, B, I\right)}{\partial B}>0
$$

Thus, the effects of $T 2$ on $s_{1}^{*}, p_{2}, e_{2}^{*}$, and $p_{2} e_{2}^{*}$ are indeterminate, even when there are strong treatment effects on the likelihood of participants visiting the VEC website and claiming the bonus.

\subsection{Hypotheses}

The model predictions suggest a number of testable hypotheses about the treatment effects of $T 1$ and $T 2$ relative to the control group $C$. The first set of hypotheses is concerned with the likelihood of participants comparing electricity offers by various retailers at the VEC website:

H1.1: $T 1$ increases participants' likelihood of visiting the VEC website to compare prices.

H1.2: $T 2$ increases participants' likelihood to visiting the VEC website to compare prices.

H1.3: We expect the effect under H1.2 to be larger than the effect under H1.1 since $T 2$ participants see greater gains from visiting the VEC website than $T 1$ participants.

The second set of hypotheses is concerned with the likelihood of participants claiming the $\$ 50$ bonus via the VEC website:

H2.1: $T 1$ increases participants' likelihood to claim the $\$ 50$ bonus.

H2.2: $T 2$ increases participants' likelihood to claim the $\$ 50$ bonus.

$\mathrm{H} 2.3$ : We expect the effect under $\mathrm{H} 2.2$ to be larger than the effect under $\mathrm{H} 2.1$ because $T 2$ participants see the availability of the $\$ 50$ bonus before visiting the VEC website, while $T 1$ participants would only see the availability of the $\$ 50$ bonus after visiting the VEC website.

The third set of hypotheses is concerned with the likelihood of participants contacting or switching retailers:

H3.1: $T 1$ increases participants' likelihood of contacting or switching retailers if the income effect from the bonus is small.

H3.2: T2 increases participants' likelihood of contacting or switching retailers if the income effect from the bonus is small.

H3.3: We expect the effect under H3.2 to be larger than the effect under H3.1 because $T 2$ participants are expected to have a higher likelihood of visiting the VEC website to compare prices under H1.3.

The fourth set of hypotheses is concerned with the unit cost of electricity:

H4.1: T1 lowers the unit cost of electricity paid when H3.1 holds. 
H4.2: $T 2$ lowers the unit cost of electricity paid when H3.2 holds.

H4.3: We expect the effect under H4.2 to be larger than the effect under H4.1 because T2 participants are expected to have greater likelihood of contacting and switching retailers under H3.3.

The fifth set of hypotheses is concerned with electricity consumption:

H5.1: $T 1$ increases electricity consumption when H4.1 holds.

H5.2: $T 2$ increases electricity consumption when H4.2 holds.

H5.3: We expect the effect under H5.2 to be larger than the effect under H5.1 because T2 participants are expected to experience a larger fall in the unit cost of electricity under H4.3.

The six set of hypotheses is concerned with electricity expenditure:

H6.1: If demand is price inelastic, $T 1$ decreases electricity expenditure when H4.1 and H5.1 hold.

H6.2: If demand is price inelastic, $T 2$ decreases electricity expenditure when H4.2 and H5.2 hold.

H6.3: We expect the effect under H6.2 to be larger than the effect under H6.1 because $T 2$ participants are expected to experience a larger fall in the unit cost of electricity under H4.3.

\subsubsection{Heterogenous effects}

Since our model predictions indicate that the effect of receiving the bonus on a consumer's effort to search and contact retailers for better energy deals heavily depends on the income effect of the bonus, we also analyse the treatment effects by income group. We expect low-income participants to be more sensitive to the bonus payment than high-income participants as the bonus payment represents a greater share of the income of low-income participants. Thus, the income effect is likely to be more relevant for low-income participants. Specifically, we hypothesise that providing information about the availability of the bonus (T2) to low-income participants may lead to:

H7.1: A non-positive effect on the likelihood of contacting or switching retailers.

H7.2: A non-negative effect on the unit cost of electricity.

H7.3: A negative effect on electricity consumption if the negative effect of the price increase dominates the positive consumption effect of the bonus.

\section{Empirical specification and data}

\subsection{Empirical specification:}

We estimate the following regression model to test hypotheses H1.1 to H6.3.

$$
{ }_{i}=\alpha_{0}+\alpha_{1}{ }_{1} 1_{i}+\alpha_{2}{ }_{2} 2+X_{i}+\epsilon_{i}
$$


where $Y$ represents one of the six dependent variables: (i) comparing deals through the VEC website; (ii) claiming the $\$ 50$ bonus; (iii) contacting or switching retailers; (iv) the logarithm of follow-up electricity costs per $\mathrm{kWh}$; (v) the logarithm of follow-up electricity consumption; and (vi) the logarithm of follow-up electricity expenditure. $T 1$ and $T 2$ represent the two treatment groups. When we examine the effects of treatments on the logarithm of follow-up electricity costs per $\mathrm{kWh}$, the logarithm of follow-up electricity consumption and the logarithm of follow-up electricity expenditure, we control for their baseline measure by including the logarithm of baseline electricity costs per $\mathrm{kWh}$, the logarithm of baseline electricity consumption or the logarithm of baseline electricity expenditure in $X_{i}$ in Equation (1), in order to improve the precision of the estimates. $\alpha_{0}$ and $\epsilon_{i}$ are the constant and error term respectively. $T 1$ takes the value one if the participant is assigned to the first treatment group that only receives information at baseline about average cost savings from the VEC website. $T 2$ takes the value one if the participant is assigned to the second treatment group that receives information about average cost savings from the VEC website and the $\$ 50$ bonus for visiting the site. We are interested in the coefficients $\alpha_{1}$ and $\alpha_{2}$, that characterize any differences between the control $(C)$ and treatments (T1 or $T 2){ }^{8}$

\subsection{Summary Statistics by Treatment and Verification of Randomization}

In this section, we report the summary statistics of participants by treatment and provide evidence that we successfully randomized the assignment of treatments. Our tests of balance concentrate on the outcome measures of interest at baseline.

Table 2 reports the mean and standard deviation for characteristics of the full sample by treatment, which shows that these characteristics are balanced across treatment arms. The $p$-values for the joint tests of difference between control and $T 1$, as well as control and $T 2$, are mostly above 0.10 . This suggests that demographic and socioeconomic characteristics are homogenous across treatment arms. Participants are, on average, 42.48-44.66 years old and the majority are female (59-65\%). Participants are well-distributed at different levels of income and educational attainment. The majority of participants have a bachelor's degree or above and around $50-53 \%$ of the participants have a weekly

\footnotetext{
${ }^{8}$ We are interested in the average treatment effect (ATE) that estimates the effect of treatment on the population of interest ( $T 1$ or $T 2$ ). In our model $Y_{i}^{1}$ is the outcome variable given that respondent $i$ has received the treatment $(T 1$ or $T 2)$, while $Y_{i}^{0}$ is the outcome variable without treatments $(C)$. In our settings, ATE is the average treatment effect that captures the difference of these potential outcomes over the population of interest, where $A T E=E\left[Y_{i}^{1}-Y_{i}^{0}\right]$. Note that the Victoria Default Offer (VDO) was implemented on the $1^{\text {st }}$ of July 2019. Under the VDO, energy providers are required by law to tell consumers on their bills, at least once every three months for electricity accounts and once every four months for gas accounts, whether they are receiving their best offer. Since all consumers received such information, and we randomly assigned participants into treatment groups, out treatments are orthogonal to the introduction of the VDO.
} 
income of $\$ 1,499$ (yearly $\$ 77,999$ ) or less. Roughly $70 \%$ of individuals in our sample were with Tier1 retailers at baseline $(69 \%$ in $C ; 71 \%$ in $T 1 ; 71 \%$ in $T 2)$, and this share is similar across treatments. ${ }^{9}$ Between $10 \%$ and $14 \%$ of respondents in our sample own solar panels and the differences are not statistically different across treatments. Participants spend, on average, \$233-\$250 per billing cycle, while, in terms of cost per $\mathrm{kWh}$, it is around $\$ 0.59-0.85 .{ }^{10}$ Note that the standard deviation of unit cost is also fairly significant at baseline, suggesting large potential gains from renegotiating prices with current retailers or switching to new retailers. On average, participants' baseline electricity consumption is in the range of $695-750 \mathrm{kWh}$. At baseline, participants' tendency to contact retailers to inquire about offers/products/prices is similar in the range of $0.38-0.40$. Our sample, in terms of income and electricity consumption, is broadly representative of the Victorian population. ${ }^{11}$

\section{Results}

\subsection{Average treatment effects}

Table 3 represents the regression results as marginal effects from an OLS regression with robust standard errors in parentheses. The results for the effect of each treatment on the likelihood of participants using the VEC site to compare energy deals across energy retailers are presented in Column (1). Participants (T1) who received information about the potential cost savings from using the VEC website, but were not told about the $\$ 50$ bonus, are not statistically more likely to visit the VEC website to compare energy deals compared to participants in the control group $(C)$. In contrast, participants (T2) who were given information about the $\$ 50$ bonus and the potential cost savings from using the VEC website are 13.7 percentage points more likely to use the VEC website to compare energy deals offered by different retailers, relative to participants $(C)$ who received no such information. This result implies that just providing information about the benefits of a comparison site is not enough to motivate consumers to use the website to find competitive offers on the market. Rather, offering a financial incentive motivates participants to use the comparison site to find other offers. This result is consistent with hypotheses H1.2 and H1.3, but not H1.1.

\footnotetext{
9 Tier 1 retailers are Alinta Energy, AGL, EnergyAustralia, Origin Energy, Red Energy, Lumo Energy, and Simply Energy (AEMC 2019). Roughly 85\% of Victorian households have one of them as their energy providers in $2018-2019$.

${ }^{10}$ The distribution of prices is quite skewed at the baseline. Although the mean is around 0.70 at baseline, the median is actually 0.34 . In the follow up, the mean falls to 0.36 , while the median becomes 0.32 . When usage is high, the fixed component (such as supply charge) of the bill is spread over a larger base, so cost per kWh falls when the consumption level increases. These median prices are very similar to the annual median price of 0.31 for a sample of Victorian households in 2018-2019 as reported in Mountain and Burns (2020).

${ }^{11}$ Victorian median weekly household income was $\$ 1,419$ in 2016 (ABS 2016). After adjusting for inflation, the amount becomes $\$ 1,475$, which falls within our sample median income range $(\$ 1250$ - \$1,499). The annual average electricity consumption in our sample is approximately 4.89 MWh. It is similar to the 4.91 MWh figure for a sample of Victorian households in 2018-2019 as reported in Mountain and Burns (2020).
} 
Table 2: Verification of randomization

\begin{tabular}{|c|c|c|c|c|c|c|c|}
\hline & $\begin{array}{c}\text { Control } \\
\text { Mean } \\
\text { (Std. err.) }\end{array}$ & SD & $\begin{array}{c}\text { T1 } \\
\text { Mean } \\
\text { (Std. err.) }\end{array}$ & $\mathrm{SD}$ & $\begin{array}{c}\text { T2 } \\
\text { Mean } \\
\text { (Std. err.) }\end{array}$ & SD & $\begin{array}{c}\text { F-stat } \\
(p \text {-value })\end{array}$ \\
\hline Age & $\begin{array}{l}42.48 \\
(0.93)\end{array}$ & 14.75 & $\begin{array}{l}42.00 \\
(0.90)\end{array}$ & 14.37 & $\begin{array}{l}44.66 \\
(0.92)\end{array}$ & 14.62 & $\begin{array}{c}2.37 \\
(0.09)\end{array}$ \\
\hline Male $(=1)$ & $\begin{array}{c}0.41 \\
(0.03)\end{array}$ & 0.49 & $\begin{array}{c}0.34 \\
(0.03)\end{array}$ & 0.47 & $\begin{array}{c}0.37 \\
(0.03)\end{array}$ & 0.48 & $\begin{array}{c}1.18 \\
(0.31)\end{array}$ \\
\hline Female $(=1)$ & $\begin{array}{c}0.59 \\
(0.03)\end{array}$ & 0.49 & $\begin{array}{c}0.65 \\
(0.03)\end{array}$ & 0.48 & $\begin{array}{c}0.63 \\
(0.03)\end{array}$ & 0.48 & $\begin{array}{c}1.04 \\
(0.35)\end{array}$ \\
\hline Education: Bachelor's degree or above $(=1)$ & $\begin{array}{c}0.57 \\
(0.03)\end{array}$ & 0.50 & $\begin{array}{c}0.48 \\
(0.03)\end{array}$ & 0.50 & $\begin{array}{c}0.56 \\
(0.03)\end{array}$ & 0.50 & $\begin{array}{c}2.53 \\
(0.08)\end{array}$ \\
\hline Income: $\$ 1,499$ per week or less $(=1)^{\mathrm{a}}$ & $\begin{array}{c}0.53 \\
(0.03)\end{array}$ & 0.50 & $\begin{array}{c}0.50 \\
(0.03)\end{array}$ & 0.50 & $\begin{array}{c}0.53 \\
(0.03)\end{array}$ & 0.50 & $\begin{array}{c}0.19 \\
(0.82)\end{array}$ \\
\hline Log baseline expenditure (\$) & $\begin{array}{c}5.18 \\
(0.05)\end{array}$ & 0.76 & $\begin{array}{c}5.17 \\
(0.05)\end{array}$ & 0.77 & $\begin{array}{c}5.15 \\
(0.05)\end{array}$ & 0.81 & $\begin{array}{c}0.11 \\
(0.89)\end{array}$ \\
\hline Log baseline consumption in $\mathrm{kWh}$ & $\begin{array}{c}6.15 \\
(0.07)\end{array}$ & 1.04 & $\begin{array}{c}6.18 \\
(0.06)\end{array}$ & 0.93 & $\begin{array}{c}6.13 \\
(0.06)\end{array}$ & 1.02 & $\begin{array}{c}0.21 \\
(0.81)\end{array}$ \\
\hline Log baseline cost per $\mathrm{kWh}(\$)^{\mathrm{b}}$ & $\begin{array}{l}-0.97 \\
(0.05)\end{array}$ & 0.77 & $\begin{array}{l}-1.00 \\
(0.04)\end{array}$ & 0.67 & $\begin{array}{l}-0.98 \\
(0.04)\end{array}$ & 0.66 & $\begin{array}{c}0.15 \\
(0.86)\end{array}$ \\
\hline Made inquiry with energy retailer in baseline & $\begin{array}{c}0.40 \\
(0.03)\end{array}$ & 0.49 & $\begin{array}{c}0.38 \\
(0.03)\end{array}$ & 0.49 & $\begin{array}{c}0.42 \\
(0.03)\end{array}$ & 0.49 & $\begin{array}{c}0.31 \\
(0.73)\end{array}$ \\
\hline Client of a Tier1 retailer in baseline & $\begin{array}{c}0.69 \\
(0.03)\end{array}$ & 0.46 & $\begin{array}{c}0.71 \\
(0.03)\end{array}$ & 0.46 & $\begin{array}{c}0.71 \\
(0.03)\end{array}$ & 0.45 & $\begin{array}{c}0.19 \\
(0.83)\end{array}$ \\
\hline Solar panel ownership in baseline & $\begin{array}{c}0.14 \\
(0.02)\end{array}$ & 0.35 & $\begin{array}{c}0.13 \\
(0.02)\end{array}$ & 0.33 & $\begin{array}{c}0.10 \\
(0.02)\end{array}$ & 0.30 & $\begin{array}{l}1.20 \\
(0.30)\end{array}$ \\
\hline Baseline expenditure (\$) & $\begin{array}{l}242.58 \\
(15.61)\end{array}$ & 246.85 & $\begin{array}{l}249.88 \\
(24.62)\end{array}$ & 389.27 & $\begin{array}{l}232.51 \\
(11.76)\end{array}$ & 186.36 & $\begin{array}{c}0.27 \\
(0.77)\end{array}$ \\
\hline Baseline consumption in $\mathrm{kWh}$ & $\begin{array}{l}749.77 \\
(61.25)\end{array}$ & 968.52 & $\begin{array}{r}762.09 \\
(80.04)\end{array}$ & 1265.53 & $\begin{array}{l}694.66 \\
(40.27)\end{array}$ & 638.02 & $\begin{array}{c}0.45 \\
(0.64)\end{array}$ \\
\hline Baseline cost per kWh $(\$)$ & $\begin{array}{c}0.85 \\
(0.24)\end{array}$ & 3.79 & $\begin{array}{c}0.59 \\
(0.14)\end{array}$ & 2.17 & $\begin{array}{c}0.65 \\
(0.15)\end{array}$ & 2.34 & $\begin{array}{c}0.44 \\
(0.65)\end{array}$ \\
\hline Baseline sample size & 251 & & 250 & & 251 & & \\
\hline
\end{tabular}

Notes: (a) The median income level in Victoria is $\$ 1,419$ per week (ABS 2016). (b) The cost per kWh is the ratio of total expenditure to total units consumed. 
Table 3: Effect of treatments on outcomes of interest for all households.

\begin{tabular}{|c|c|c|c|c|c|c|}
\hline & $\begin{array}{c}\text { (1) } \\
\text { Compare deals at } \\
\text { VEC site }\end{array}$ & $\begin{array}{c}\text { (2) } \\
\text { Claim bonus via } \\
\text { VEC site } \\
\end{array}$ & $\begin{array}{c}\text { (3) } \\
\text { Contact with } \\
\text { retailers for change }\end{array}$ & $\begin{array}{l}\text { (4) } \\
\text { Log follow-up cost } \\
\text { per kWh }(\$)\end{array}$ & $\begin{array}{c}(5) \\
\text { Log follow-up } \\
\text { consumption }(\mathrm{kWh}) \\
\end{array}$ & $\begin{array}{c}\text { (6) } \\
\text { Log follow-up } \\
\text { expenditure (\$) }\end{array}$ \\
\hline$T 1:$ VEC site info & $\begin{array}{c}0.0441 \\
(0.0633)\end{array}$ & $\begin{array}{l}0.148 * * \\
(0.0655)\end{array}$ & $\begin{array}{l}-0.0180 \\
(0.0634)\end{array}$ & $\begin{array}{l}-0.0599 \\
(0.0859)\end{array}$ & $\begin{array}{c}0.131 \\
(0.0996)\end{array}$ & $\begin{array}{c}0.0369 \\
(0.0893)\end{array}$ \\
\hline T2: VEC site $\&$ bonus info & $\begin{array}{l}0.137 * * \\
(0.0640)\end{array}$ & $\begin{array}{c}0.194 * * * \\
(0.0642)\end{array}$ & $\begin{array}{c}-0.0998^{*} \\
(0.0580)\end{array}$ & $\begin{array}{c}0.128 \\
(0.0827)\end{array}$ & $\begin{array}{l}0.0562 \\
(0.106)\end{array}$ & $\begin{array}{c}0.153 * \\
(0.0868)\end{array}$ \\
\hline Log baseline expenditure (\$) & & & & & & $\begin{array}{c}0.878 * * * \\
(0.0626)\end{array}$ \\
\hline Log baseline consumption (kWh) & & & & & $\begin{array}{c}0.718 * * * \\
(0.0977)\end{array}$ & \\
\hline Log baseline cost per kWh (\$) & & & & $\begin{array}{c}0.198 * * * \\
(0.0761)\end{array}$ & & \\
\hline Constant & $\begin{array}{c}0.237 * * * \\
(0.0434)\end{array}$ & $\begin{array}{c}0.227 * * * \\
(0.0427)\end{array}$ & $\begin{array}{c}0.268 * * * \\
(0.0452)\end{array}$ & $\begin{array}{c}-1.019 * * * \\
(0.0925)\end{array}$ & $\begin{array}{c}1.814 * * * \\
(0.643)\end{array}$ & $\begin{array}{c}0.514 \\
(0.333)\end{array}$ \\
\hline Observations & 300 & 300 & 300 & 300 & 300 & 300 \\
\hline
\end{tabular}

Notes: Robust standard errors in parentheses $* * * \mathrm{p}<0.01, * * \mathrm{p}<0.05, * \mathrm{p}<0.1$. 
The results for the effect of each treatment on claiming the $\$ 50$ bonus via the VEC website are presented in column (2) of Table 3. We find that providing information about the potential cost savings from using the VEC website (T1) alone and providing information about both the cost savings from using the VEC website and the $\$ 50$ bonus (T2) increase the probability of claiming the bonus by 14.8 and 19.4 percentage points for $T 1$ and $T 2$ respectively compared to participants $(C)$ who receive none of the information. In terms of magnitude, we find that the coefficient on $T 2(0.193)$ is greater than the coefficient on $T 1$ (0.148) and that the $F$-test results (5.11) with corresponding $p$-value $=0.007$ confirm that these coefficients are significantly different from each other. This supports our hypothesis H2.3, suggesting that the likelihood of claiming the $\$ 50$ bonus is higher among $T 2$ participants than among $T 1$ participants. This result is consistent with our hypothesis H2.1, H2.2 and H2.3.

Interestingly, even though participants in $T 1$ were not more likely to compare energy deals via the VEC website, they end up claiming the $\$ 50$ bonus. A possible explanation for this result is that VEC site users can claim the $\$ 50$ bonus without actually comparing energy offers across retailers because the opportunity to claim the $\$ 50$ bonus becomes available before consumers actually compare offers, while we specifically asked participants whether they used the VEC site to compare energy offers (see section 2.2). ${ }^{12}$ Thus, participants who claimed the $\$ 50$ bonus via the VEC website, but did not actually compare energy deals, might answer no to that question.

Column 3 in Table 3 reports the effect of each treatment on the participant's likelihood of contacting retailers, or switching their retailer, to get a better deal. This entails either renegotiating the price charged or the discount given by their current retailers or switching to a new retailer with a better offer. We do not find any significant effect of the $T 1$ treatment, while the $T 2$ treatment has a negative effect. These results imply that, compared with $C$ participants, $T 2$ participants are 10 percentage points less likely to contact their energy retailers to get a better deal or to switch. Hence, the results are not consistent with hypotheses H3.1, H3.2 and H3.3 that $T 1$ and $T 2$ increase the likelihood of contacting or switching retailers. The significant negative impact of treatment on $T 2$ participants implies that the income effect from the bonus is likely to be fairly strong, potentially raising the relative value of leisure $\left(l_{1}\right)$ and, thereby, reducing search and contact activities $\left(s_{1}\right)$. This interpretation is consistent with the finding that $T 2$ participants are significantly more likely to claim the $\$ 50$ bonus. In contrast, even though the likelihood of claiming the $\$ 50$ bonus is also significantly greater for $T 1$ participants than $C$ participants, their likelihood of contacting or switching retailers is not statistically different. One

\footnotetext{
${ }^{12}$ Note that the VEC website fixed this feature after our experiment concluded.
} 
plausible explanation is that compared with $T 2$ participants, $T 1$ participants are less likely to claim the bonus ( 0.148 versus 0.194 in column 3$)$, and, hence, the income effect for them is smaller.

In Column 4 and 5 in Table 3, we do not find any statistically significant impact of treatments on follow-up cost per unit $\mathrm{kWh}$ and total consumption $(\mathrm{kWh})$ of electricity. These results, thus, are not consistent with hypotheses H4.1-H4.3 and H5.1-H5.3. However, note that although these estimates are not statistically significant, $T 2$ participants experienced a $12.8 \%$ increase in their unit cost of electricity in the follow-up survey, which is at least consistent with their lower likelihood of contacting, or switching, retailers. In Column 6, we do not find any evidence of expenditure increase for $T 1$ participants, but we find that total follow-up electricity expenditure increases by $15.3 \%$ for $T 2$ participants, compared with $C$ participants. It is interesting to note here that, instead of decreasing electricity expenditure (hypothesis H6.1), T2 increases electricity expenditure. This result is consistent with the large increase in unit electricity cost and the increase in electricity consumption that $T 2$ participants experienced, even though the estimates are noisy.

\subsection{Heterogeneous treatment effects}

The inconsistency in the average effects of $T 2$ across contact and switch effort, unit cost, consumption and expenditure may be driven by income heterogeneity. We now examine whether heterogeneous treatment effects by income group are driving these patterns. Specifically, the income effect from claiming the bonus might affect the search and contact activities of participants from different income groups differently. Specifically, it is reasonable to expect that the increase in income from the provision of the bonus might have a stronger effect on low-income participants than high-income participants, leading the former to reduce effort expended on searching, and contacting retailers, for better deals.

Table 4 reports the treatment effects for low-income participants. In column (1), we find that lowincome $T 1$ participants are not statistically more likely to visit the VEC website compared to participants in the control group $(C)$. However, $T 2$ participants are 17 percentage points more likely to compare energy deals at the VEC website compared to control participants $(C)$. In column (2), we find that $T 1$ participants are not statistically more likely to claiming the $\$ 50$ bonus via the VEC website compared to participants in the control group $(C)$, but low-income $T 2$ participants are 22 percentage points more likely to claim the $\$ 50$ bonus compared to control participants $(C)$. Intuitively, the additional information in T2 that some "free money" is available attracts people, especially lowincome individuals, to check out the VEC website. Because of randomization, we can attribute the increased likelihood of visiting the website and claiming the bonus to the information provided. 
In column (3), we do not find any significant effect of $T 1$ on low-income participants' likelihood of contacting retailers for a change, but $T 2$ decreased participants' likelihood of contacting retailers for a change by 15.7 percentage points, consistent with H7.1. This result is consistent with Gulati et al.'s (2017) argument that for households with severe liquidity constraints, behavioural heuristics may act to amplify the gains as the bonus frees these households from engaging in arduous search and haggling activities. It is also consistent with Byrne et al.'s (2019) argument that low-income households in Victoria search less for deals when the State Government of Victoria pays them $17.5 \%$ of their annual electricity costs above and beyond the first $\$ 171.60$ of their electricity costs.

In column (4), we find that, compared with control group participants, there is no significant change in the cost of per unit kWh electricity for low-income $T 1$ participants, while the cost of per unit $\mathrm{kWh}$ electricity has significantly increased by $26.8 \%$ for low-income $T 2$ participants. This result is consistent with $\mathrm{H} 7.2$ that there is a non-negative effect of treatment $T 2$ on the unit cost of electricity low-income participants paid. This finding is also consistent with the result reported in column (3). As low-income $T 2$ participants reduced their effort to search and contact retailers for a better deal, they ended up paying a higher unit cost of electricity, relative to low-income $C$ participants.

In column (5), neither treatment has any significant impact on low-income participants' follow-up total electricity consumption ( $\mathrm{kWh}$ ), inconsistent with H7.3. The increase in electricity price does not make any significant differences to the level of electricity consumption for low-income consumers. This is consistent with the fact that the demand for electricity is highly inelastic, at least in the short run.

In column (6), we do not observe any significant effect of $T 1$ on the expenditure of low-income participants, which is consistent with the fact that we do not find any significant effects of $T 1$ on their effort to contact retailers for a change, their follow-up unit cost of electricity and follow-up electricity consumption level. In contrast, we find evidence that the total electricity expenditure of low-income participants is $29.9 \%$ higher for $T 2$ participants than for $C$ participants. This result is consistent with the findings in column (4) and (5) as it implies that the increase in total expenditure of low-income $T 2$ participants is due to the higher price that they paid relative to low-income $C$ participants.

Table 5 reports the effects of treatments for high-income participants. In column (1), we do not find any evidence that either $T 1$ or $T 2$ affects high-income participants' likelihood of comparing energy deals through visiting the VEC website. In column (2), we find that both $T 1$ and $T 2$ increase high- 
income participants' likelihood of claiming the $\$ 50$ bonus by 16.5 and 16.4 percentage points respectively. The results suggest that high-income participants are not interested in using price comparison sites to get information about better energy offers. A potential explanation is that for highincome participants, the expected and uncertain amount of saving is not worth their time cost in comparing prices and contacting retailers for a change. However, they still take the opportunity to claim the $\$ 50$ bonus as that process is fast and the result is certain.

In column (3), $T 1$ or $T 2$ has no effect on high-income participants' likelihood of contacting retailers for a change. The findings here contrast with the findings for low-income participants. First, as column (1) indicates that high-income participants did not use the VEC site to compare energy deals, it is reasonable to expect that they also did not contact any retailers for a change. Second, the $\$ 50$ bonus represents a small portion of their income and is unlikely to generate any significant income effect to induce them to change their search and contact activities. In Columns (4) to (6), neither treatment affects high-income participants' follow-up unit electricity costs, electricity consumption and electricity expenditure. These results are consistent with the findings in column (3). As the treatments did not affect high-income participants' effort to contact retailers for a better deal or to switch retailers, it is expected that their follow-up unit electricity costs, electricity consumption and electricity expenditure would remain unchanged, relative to high-income participants in the control group.

In sum, we find heterogeneous treatment effects for low-income and high-income participants. The provision of the $\$ 50$ bonus via the VEC site led to unintended consequences. After receiving the $\$ 50$ bonus, low-income $T 2$ participants reduced their effort to contact, or switch, retailers in order to secure a better offer. As a consequence, they ended up paying higher electricity prices, relative to low-income $C$ participants who did not claim the $\$ 50$ bonus. As these low-income $T 2$ participants pay higher electricity prices without changing their consumption level, their electricity expenditure increases as a result of the financial incentives. Therefore, the policy of providing financial incentive makes lowincome households worse off in net terms, at least in the short term.

On the other hand, our results suggest that high-income participants in both treatment groups claimed the $\$ 50$ bonus without actually comparing energy offers at the VEC website. These high-income participants' electricity prices, consumption levels and expenditure remained unchanged in the followup survey, relative to participants in the control group. 
Table 4: Effect of treatments on outcomes of interest for the low-income households.

\begin{tabular}{|c|c|c|c|c|c|c|}
\hline & $\begin{array}{c}(1) \\
\text { Compare deals at } \\
\text { VEC site }\end{array}$ & $\begin{array}{l}\text { (2) } \\
\text { Claim bonus via } \\
\text { VEC site }\end{array}$ & $\begin{array}{c}(3) \\
\text { Contact with retailers } \\
\text { for change }\end{array}$ & $\begin{array}{l}(4) \\
\text { Log follow-up cost } \\
\text { per kWh }(\$)\end{array}$ & $\begin{array}{c}(5) \\
\text { Log follow-up } \\
\text { consumption }(\mathrm{kWh})\end{array}$ & $\begin{array}{c}(6) \\
\text { Log follow-up } \\
\text { expenditure (\$) }\end{array}$ \\
\hline$T 1:$ VEC site info & $\begin{array}{c}0.0884 \\
(0.0943)\end{array}$ & $\begin{array}{c}0.135 \\
(0.0975)\end{array}$ & $\begin{array}{l}0.00680 \\
(0.0981)\end{array}$ & $\begin{array}{l}0.0689 \\
(0.121)\end{array}$ & $\begin{array}{c}-0.0560 \\
(0.151)\end{array}$ & $\begin{array}{c}0.0728 \\
(0.130)\end{array}$ \\
\hline T2: VEC site $\&$ bonus info & $\begin{array}{c}0.170 * \\
(0.0924)\end{array}$ & $\begin{array}{l}0.225 * * \\
(0.0942)\end{array}$ & $\begin{array}{l}-0.157 * \\
(0.0854)\end{array}$ & $\begin{array}{c}0.268 * * \\
(0.111)\end{array}$ & $\begin{array}{l}0.0366 \\
(0.151)\end{array}$ & $\begin{array}{c}0.299 * * \\
(0.116)\end{array}$ \\
\hline Log baseline expenditure (\$) & & & & & & $\begin{array}{c}0.897 * * * \\
(0.100)\end{array}$ \\
\hline Log baseline consumption (kWh) & & & & & $\begin{array}{c}0.601 * * * \\
(0.143)\end{array}$ & \\
\hline Log baseline Cost per kWh (\$) & & & & $\begin{array}{l}0.212 * * \\
(0.0889)\end{array}$ & & \\
\hline Constant & $\begin{array}{c}0.245 * * * \\
(0.0621)\end{array}$ & $\begin{array}{c}0.265 * * * \\
(0.0637)\end{array}$ & $\begin{array}{c}0.327 * * * \\
(0.0677)\end{array}$ & $\begin{array}{c}-1.093 * * * \\
(0.114)\end{array}$ & $\begin{array}{c}2.644 * * * \\
(0.945)\end{array}$ & $\begin{array}{c}0.418 \\
(0.538)\end{array}$ \\
\hline Observations & 147 & 147 & 147 & 147 & 147 & 147 \\
\hline
\end{tabular}

Notes: Robust standard errors in parentheses $* * * \mathrm{p}<0.01,{ }^{* *} \mathrm{p}<0.05,{ }^{*} \mathrm{p}<0.1$. 
Table 5: Effect of treatments on outcomes of interest for the high-income households.

\begin{tabular}{|c|c|c|c|c|c|c|}
\hline & $\begin{array}{l}(1) \\
\text { Compare deals at VEC } \\
\text { site }\end{array}$ & $\begin{array}{l}(2) \\
\text { Claim bonus via } \\
\text { VEC site }\end{array}$ & $\begin{array}{c}(3) \\
\text { Contact with retailers } \\
\text { for change }\end{array}$ & $\begin{array}{c}(4) \\
\text { Log follow-up } \\
\text { cost per kWh }(\$)\end{array}$ & $\begin{array}{c}(5) \\
\text { Log follow-up } \\
\text { consumption }(\mathrm{kWh})\end{array}$ & $\begin{array}{c}(6) \\
\text { Log follow-up } \\
\text { expenditure (\$) }\end{array}$ \\
\hline T1: VEC site info & $\begin{array}{c}0.00613 \\
(0.0857)\end{array}$ & $\begin{array}{c}0.165^{*} \\
(0.0883)\end{array}$ & $\begin{array}{c}-0.0319 \\
(0.0801)\end{array}$ & $\begin{array}{l}-0.185 \\
(0.123)\end{array}$ & $\begin{array}{c}0.221 \\
(0.155)\end{array}$ & $\begin{array}{c}0.00746 \\
(0.125)\end{array}$ \\
\hline T2: VEC site \& bonus info & $\begin{array}{c}0.104 \\
(0.0892)\end{array}$ & $\begin{array}{c}0.164 * \\
(0.0869)\end{array}$ & $\begin{array}{c}-0.0417 \\
(0.0783)\end{array}$ & $\begin{array}{r}-0.0151 \\
(0.124)\end{array}$ & $\begin{array}{l}0.0203 \\
(0.139)\end{array}$ & $\begin{array}{c}0.00981 \\
(0.127)\end{array}$ \\
\hline Log baseline expenditure $(\$)$ & & & & & & $\begin{array}{c}0.889 * * * \\
(0.0784)\end{array}$ \\
\hline Log baseline consumption (kWh) & & & & & $\begin{array}{c}0.854 * * * \\
(0.0949)\end{array}$ & \\
\hline Log baseline Cost per kWh (\$) & & & & $\begin{array}{c}0.120 \\
(0.153)\end{array}$ & & \\
\hline Constant & $\begin{array}{c}0.229 * * * \\
(0.0613)\end{array}$ & $\begin{array}{c}0.187 * * * \\
(0.0569)\end{array}$ & $\begin{array}{c}0.208 * * * \\
(0.0592)\end{array}$ & $\begin{array}{c}-1.008^{* * *} \\
(0.161)\end{array}$ & $\begin{array}{c}0.885 \\
(0.629)\end{array}$ & $\begin{array}{c}0.449 \\
(0.414)\end{array}$ \\
\hline Observations & 153 & 153 & 153 & 153 & 153 & 153 \\
\hline
\end{tabular}

Notes: Robust standard errors in parentheses ${ }^{* * *} \mathrm{p}<0.01,{ }^{* *} \mathrm{p}<0.05,{ }^{*} \mathrm{p}<0.1$. 


\section{Conclusion}

There is increasing interest in government-sponsored comparison websites as a vehicle to promote competition and lower prices, in particular in energy markers, in Australia, New Zealand and the United Kingdom. Yet, the efficacy of such websites has not been examined. We conducted an online randomized controlled experiment to examine whether the government-owned VEC website has been effective in getting consumers to switch to cheaper retailers or renegotiate better offers with their existing retailer. We take advantage of the $\$ 50$ bonus offered by the Victorian government to use the VEC website between 1st July 2018 and 30th June 2020 to test whether offering a financial incentive encourages consumers to visit the website and ultimately switch or negotiate a better deal.

The main takeaway from our study is that comparison websites, such as VEC, may not increase competition and can worsen outcomes for low-income consumers. We find that providing participants with information about the average cost savings from using the site and providing this information plus informing them of the availability of a $\$ 50$ bonus for visiting the site, increases the likelihood that participants in the two treatments visit the site, relative to those in the control. However, neither the provision of information about the potential cost savings from switching, nor informing them of the cost savings and the availability of the bonus increased the likelihood that participants in the treatments switched, leading to a decrease in prices paid, relative to participants in the control.

One of the main motivations for promoting the VEC website has been to reduce the price paid for, and expenditure on, electricity of low-income groups who are most susceptible to being in energy poverty, given the sharp rise in energy prices that has followed price deregulation (Thwaites et al., 2017). The results from our heterogeneity analysis, however, suggests that the VEC website is not working as intended and that for low-income consumers providing the $\$ 50$ is actually counterproductive to what the government seeks to realize. Specifically, we find that low-income consumers in $T 2$ reduce their effort to renegotiate a better deal with their existing retailer or switch to a better offer from another retailer, in response to the income effect generated from the bonus, resulting in their paying higher prices and having higher total electricity expenditure, relative to participants in the control group. Meanwhile, high-income consumers in $T 2$ claimed the bonus without the treatment having any impact on their effort to renegotiate with their existing supplier or secure a better deal with another supplier, which resulted in their electricity prices paid, electricity consumption and electricity expenditure staying unchanged. Overall, the financial incentive provided by the bonus to visit the VEC website led to the perverse, and unintended outcome of higher prices and total expenditure on electricity. 
That providing information about potential gains from switching retailers through the use of a comparison site is ineffective and providing the $\$ 50$ bonus can actually backfire suggests that to address the lack of competition in the retail energy market, policy makers need to address supply-side barriers to switching. For example, consumers may lack information about the service of smaller retailers, switching may be a lengthy process and there might be costs, such as cancellation, disconnection and reconnection fees, associated with switching. In order to increase switching rates, government can develop policies to a) simplify the switching process; and b) reduce the psychological barriers to switching by keeping consumers informed about the benefits of switching and what switching entails. Another factor is brand loyalty The three main retailers - Origin Energy, AGL and Energy Australia - have 55\% of the market share in Victoria (AEMC 2019). Seven retailers (including the Big 3), collectively known as Tier-1 retailers have about $86 \%$ of the Victorian retail electricity market share (ESC 2019). In their analysis of approximately 47,000 household electricity bills uploaded to the VEC website, Mountain and Burns (2020) find considerable evidence of a loyalty premium or loyalty tax. Overcoming inertia is difficult. Rather than offering subsidies, informing lowincome customers about low reference points might help to overcome the regressive nature of pricing structures (Byrne et al., 2019). Finally, rather than offer financial incentives to encourage consumers to use a comparison website, it might be more effective to make the financial incentives contingent upon showing a reduction in unit electricity cost or greater energy savings. 


\section{References}

ABS (2016). Australian Bureau of Statistics. 2016 Census QuickStats. Available at: $<\underline{\text { https://quickstats.censusdata.abs.gov.au/census services/getproduct/census/2016/quickstat/2 }}$ ?opendocument $>$

ACCC (2018). Restoring electricity affordability and Australia's competitive advantage. Retail Electricity Pricing Inquiry-Final Report.

AEMC (2016). Retail Competition Review 2016, Australian Energy Market Commission. Available at: $<$ https://www.aemc.gov.au/sites/default/files/content/d5a60d5b-d2dc-4219-af6051c77d8aaa4f/RPR0004-2016-Retail-Competition-Review-Final-Report-FINAL-forpublication-30-June-pdf.PDF>

AEMC. (2019). 2019 Retail Energy Competition Review, Australian Energy Market Commission. $<$ https://www.aemc.gov.au/market-reviews-advice/2019-retail-energy-competition-review

Allcott, H. (2011). Social norms and energy conservation. Journal of Public Economics, 95(9f-10), 1082-1095.

Allcott, H., \& Rogers, T. (2014). The short-run and long-run effects of behavioral interventions: Experimental evidence from energy conservation. American Economic Review, 104(10), 3003-37.

Baye, M. R., \& Morgan, J. (2001). Information gatekeepers on the internet and the competitiveness of homogeneous product markets. American Economic Review, 91(3), 454-474.

BBC 2014, Heat is on: Why are energy bills so high? viewed 07 June 2020. Available at: $<$ http://www.bbc.com/news/uk-scotland-scotland-business-25743336>

Bhargava, S., \& Manoli, D. (2015). Psychological frictions and the incomplete take-up of social benefits: Evidence from an IRS field experiment. American Economic Review, 105(11), 3489-3529.

Blumenthal, M., Christian, C., Slemrod, J., \& Smith, M. G. (2001). Do normative appeals affect tax compliance? Evidence from a controlled experiment in Minnesota. National Tax Journal, 125-138.

Bodur, H. O., Klein, N. M., \& Arora, N. (2015). Online price search: Impact of price comparison sites on offline price evaluations. Journal of Retailing, 91(1), 125-139.

Brent, D. A., Cook, J. H., \& Olsen, S. (2015). Social comparisons, household water use, and participation in utility conservation programs: Evidence from three randomized trials. Journal of the Association of Environmental and Resource Economists, 2(4), 597-627.

Brookes, L. (1990). The greenhouse effect: the fallacies in the energy efficiency solution. Energy Policy, 18(2), 199-201.

Brookes, L. (2000). Energy efficiency fallacies revisited. Energy Policy, 28(6-7), 355-366. 
Burke, P. J., \& Abayasekara, A. (2018). The price elasticity of electricity demand in the United States: A three-dimensional analysis. The Energy Journal, 39(2).

Burkhardt, J., Gillingham, K., \& Kopalle, P. K. (2019). Experimental Evidence on the Effect of Information and Pricing on Residential Electricity Consumption. NBER Working Papers 25576, National Bureau of Economic Research.

Byrne, D. P., Martin, L. A., \& Nah, J. S. (2019). Price Discrimination, Search, and Negotiation in an Oligopoly: A Field Experiment in Retail Electricity. Search, and Negotiation in an Oligopoly: A Field Experiment in Retail Electricity (December 19, 2019).

Cadena, X., \& Schoar, A. (2011). Remembering to pay? Reminders vs. financial incentives for loan payments. NBER Working Papers 17020, National Bureau of Economic Research.

Costa, D. L., \& Kahn, M. E. (2013). Energy conservation "nudges" and environmentalist ideology: Evidence from a randomized residential electricity field experiment. Journal of the European Economic Association, 11(3), 680-702.

Druckman, A., Chitnis, M., Sorrell, S., \& Jackson, T. (2011). Missing carbon reductions? Exploring rebound and backfire effects in UK households. Energy Policy, 39(6), 3572-3581.

Energy Consumers Australia (ECA). (2017). Technical Report. Energy Consumers Australia, 2017.

Essential Services Commission (ESC). (2019). Victorian energy market report 2018-19. Essential Services Commission, Melbourne.

EU Competition Authorities, (2016). Report on the monitoring exercise carried out in the online hotel booking sector by EU competition authorities in 2016. Available at: $<$ https://ec.europa.eu/competition/ecn/hotel_monitoring_report_en.pdf $>$

Fellner, G., Sausgruber, R., \& Traxler, C. (2013). Testing enforcement strategies in the field: Threat, moral appeal and social information. Journal of the European Economic Association, 11(3), 634-660.

Ferraro, P.J., Miranda, J.J. \& Price, M.K. (2011), The persistence of treatment effects with normbased policy instruments: evidence from a randomized environmental policy experiment. American Economic Review 101(3), 318-22.

Frey, B. S., \& Meier, S. (2004). Social comparisons and pro-social behavior: Testing conditional cooperation" in a field experiment. American Economic Review, 94(5), 1717-1722.

Greening, L. A., Greene, D. L., \& Difiglio, C. (2000). Energy efficiency and consumption - the rebound effect - a survey. Energy Policy, 28(6-7), 389-401.

Grubb, M. J. (1990). Communication energy efficiency and economic fallacies. Energy Policy, 18(8), 783-785. 
Gulati, S., McAusland, C., \& Sallee, J. M. (2017). Tax incidence with endogenous quality and costly bargaining: Theory and evidence from hybrid vehicle subsidies. Journal of Public Economics, 155, 93-107.

Hasseldine, J., Hite, P., James, S., \& Toumi, M. (2007). Persuasive communications: Tax compliance enforcement strategies for sole proprietors. Contemporary Accounting Research, 24(1), 171 194.

Henly, J., Ruderman, H., \& Levine, M. D. (1988). Energy saving resulting from the adoption of more efficient appliances: a follow-up. The Energy Journal, 9(2), 163-170.

Hertwich, E. G. (2005). Consumption and the rebound effect: An industrial ecology perspective. Journal of Industrial Ecology, 9(1-2), 85-98.

Hviid, M. (2015). Vertical agreements between suppliers and retailers that specify a relative price relationship between competing products or competing retailers. Paper submitted for the $124^{\text {th }}$ OECD Competition Committee.

Islam, A., Ahsanuzzaman, \& Wang, L. C. (2020). Knowhow vs. Nudges: Experimental Evidence of Non-price Energy Conservation Information on Residential Electricity Consumption (June, 2020)

Islam, A., Malek, M. A., Tasneem, S., and Wang, L. C. (2020). Can Public-recognition Backfire? Field Experimental Evidence on the Retention and Performance of Volunteers with Socialimage Concerns (June, 2020).

Johannessen, K., \& Glider, P. (2003). The University of Arizona's campus health social norms media campaign. In Perkins, H. (Ed.). The Social Norms Approach to Preventing School and College Age Substance Abuse: A Handbook for Educators, Counselors, and Clinicians. Jossey-Bass.

John, P., Sanders, M., \& Wang, J. (2014). The use of descriptive norms in public administration: a panacea for improving citizen behaviours? Available at SSRN 2514536. $<\underline{\text { https://papers.ssrn.com/sol3/papers.cfm?abstract } \mathrm{id}=2514536}>$

Kallbekken, S., Sælen, H., \& Hermansen, E. A. (2013). Bridging the energy efficiency gap: A field experiment on lifetime energy costs and household appliances. Journal of Consumer Policy, 36(1), 1-16.

Leibbrandt, A. \& List, J.A. (2018). Do equal employment opportunity statements backfire? Evidence from A natural field experiment on job-entry decisions. NBER Working Papers 25035, National Bureau of Economic Research.

Liddell, C., \& Morris, C. (2010). Fuel poverty and human health: a review of recent evidence. Energy Policy, 38(6), 2987-2997.

Lin, B., \& Liu, X. (2013). Electricity tariff reform and rebound effect of residential electricity consumption in China. Energy, 59, 240-247. 
Lovins, A. B. (1988). Energy saving from the adoption of more efficient appliances: Another view. The Energy Journal, 9(2).

Marinescu, I. (2017). The general equilibrium impacts of unemployment insurance: Evidence from a large online job board. Journal of Public Economics, 150, 14-29.

Mathios, A. D. (2000). The impact of mandatory disclosure laws on product choices: An analysis of the salad dressing market. Journal of Law and Economics, 43(2), 651-678.

Moraga-González, J. L., \& Wildenbeest, M. R. (2008). Maximum likelihood estimation of search costs. European Economic Review, 52(5), 820-848.

Mountain, B. (2019). New regulations expose energy price gouging through 'free' comparison sites $<$ https://theconversation.com/new-regulations-expose-energy-price-gouging-through-freecomparison-sites-109420>

Mountain, B., \& Burns, K. (2020). Loyalty taxes in retail electricity markets: not as they seem? Unpublished manuscript, Victoria University, Melbourne.

Nance, A. (2013). Relative energy poverty in Australia. St Kitts Associates.

Newell, R. G., \& Siikamäki, J. (2014). Nudging energy efficiency behavior: The role of information labels. Journal of the Association of Environmental and Resource Economists, 1(4), 555-598.

Newman, G. E., Gorlin, M., \& Dhar, R. (2014). When going green backfires: How firm intentions shape the evaluation of socially beneficial product enhancements. Journal of Consumer Research, 41(3), 823-839.

Ofgem (2019). State of the Market Report. Technical Report, GfK UK, SocialResearch.

Ronayne, D., \& Taylor, G. (2018). Competing sales channels. University of Oxford, Department of Economics, Working Paper, No. 843.

Swartz, J. J., Braxton, D., \& Viera, A. J. (2011). Calorie menu labeling on quick-service restaurant menus: an updated systematic review of the literature. International Journal of Behavioral Nutrition and Physical Activity, 8(1), 135.

Thaler, R. H. (1999). Mental accounting matters. Journal of Behavioral Decision Making, 12(3), 183-206.

Thwaites, J., Faulkner, P., \& Mulder, T. (2017). Independent Review into the Electricity and Gas Retail Markets in Victoria. State Government of Victoria, Melbourne.

Tyers, R., Sweeney, M., \& Moon, B. (2019). Harnessing behavioural insights to encourage consumer engagement in the British energy market: Results from a field trial. Journal of Behavioral and Experimental Economics, 80, 162-176.

VEC (2019). Victoria Energy Compare. Available at: $<$ https://www.energy.vic.gov.au/_data/assets/pdf_file/0023/404609/02_How-to-UseVictorian-Energy-Compare.pdf $>$ 